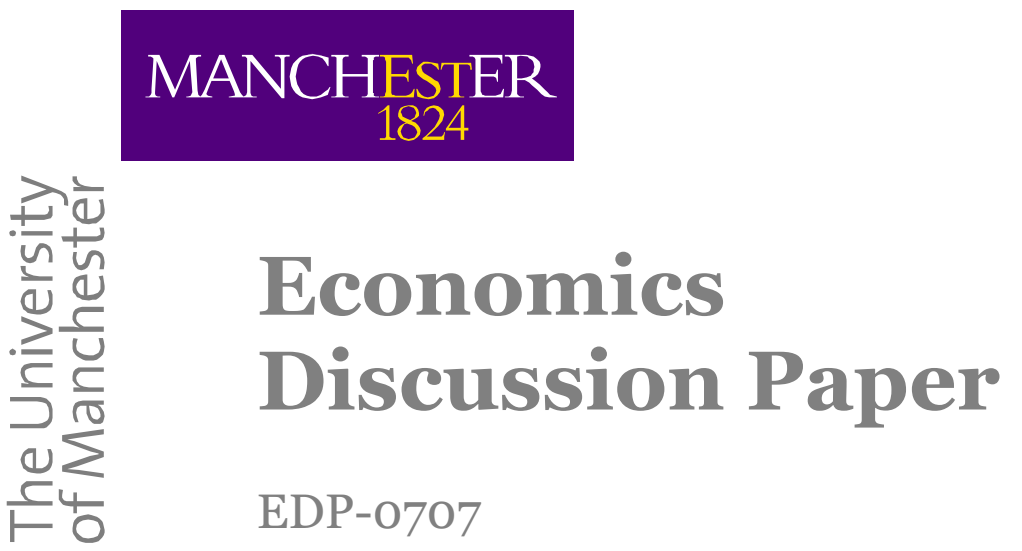

\title{
Oligopoly on a Salop circle with centre
}

\author{
By Paul Madden and Mario Pezzino
}

March 2007

Download paper from:

http://www.socialsciences.manchester.ac.uk/economics/research/discuss.htm

Economics

School of Social Sciences

The University of Manchester

Oxford Road

Manchester M13 9PL

United Kingdom 


\title{
Oligopoly on a Salop circle with centre ${ }^{\dagger}$
}

\author{
Paul Madden* \\ Mario Pezzino**
}

\begin{abstract}
We study an oligopolistic market in which consumers located around the perimeter of a Salop circle buy either from firms around this perimeter (providing horizontally differentiated goods) or from a firm located at the centre of the circle (providing a homogeneous good for consumers). An entry-pricing game is studied. The market equilibria and social optima indicate various possible market failures, some more extreme than the standard Salop excessive product differentiation. Moreover, for some parameters, the standard Salop result might be reversed.
\end{abstract}

Keywords: differentiated products, homogenous product, social optimum

JEL classification: D11, D43, L13, L81

*School of Social Sciences, University of Manchester, Manchester, M13 9PL.

E-mail:Paul.Madden@manchester.ac.uk

**School of Social Sciences, University of Manchester, Manchester, M13 9PL.

E-mail: Mario.Pezzino@manchester.ac.uk

${ }^{\dagger}$ The authors are grateful to the participants in the Economic Theory Seminars, University of Manchester, and the EEA conference, Vienna 2006.

Mario Pezzino also gratefully acknowledges ESRC support from grant number: PTA-030-2005-00988. 


\section{Introduction}

The paper studies a market in which differentiated product firms compete in prices with a homogenous product firm. Specifically there is a Salop (1979) circle on whose perimeter is located a continuum of consumers who bear transport costs if they buy (the same physical commodity of homogenous quality) from one of the firms symmetrically located on the perimeter. However, in addition, there may be a firm located at the centre of the circle, with all consumers bearing the same transport cost of buying (again, the same physical commodity of the same quality) from the central firm instead of a perimeter firm. Thus the central firm offers a homogeneous product alternative to the horizontally differentiated products of perimeter firms. Our focus is the social (sub)optimality of the market outcome modelled as subgame perfect equilibrium of an entry/pricing game, and how this differs from the standard Salop (1979) result (without the central firm) of excessive market provision of differentiated products (see e.g. Tirole (1988)).

Various previous contributions have used the geographic framework of a Salop circle with centre to study entry and pricing. Bouckaert (2000) studies a game where all the potential entrants face the same fixed costs of entry at the first stage and then choose to locate either at the centre or on the perimeter, prior to pricing at stage three. In the market outcome the (potential) competition from the centre reduces the number of firms. Balasubramanian (1998) studies the entry of a central firm into a market where the number of perimeter firms is fixed at the long run (Salop) equilibrium level. In Cheng and Nault (2006) the central location can be taken by either one (of only two) incumbents located on the perimeter, or by a new entrant. The authors show that, if the fixed entry costs are identical for incumbent and entrant, the incumbent occupies the central location first. Otherwise, an entry cost advantage (smaller is the market is not initially covered) is necessary for the new entrant in order to enter the market and locate at the centre. In all these contributions there is no discussion of social optimality of the market outcomes, our main focus. ${ }^{1}$

Also related to our analysis is Anderson and De Palma (2000) who extend the standard Salop model in a different direction, instead introducing a second dimension of product differentiation on the circle (they call it global differentiation) as well as the spatial, with a parameter capturing the relative importance of these two types of differentiation. When differentiation is predominantly spatial, each firm competes with its immediate neighbours and the standard Salop model describes this local competition; at the other extreme there is global competition, all firms competing symmetrically à la Dixit and Stiglitz (1977). The authors study the long run and short run equilibria, and their dependence on the degree of local/global competition. Among other results, they argue that the long run number of firms that enter the market is always too high from a social point of view, as in Salop (1979). Anderson and De Palma (2000) is a perfectly symmetric model. Our model of the circle with centre is asymmetric: using their terminology, on the one hand, perimeter firms compete locally with the central firm and with neighbouring firms on the perimeter; on the other hand, the central firm (the global competitor) faces only global competition. And our results show that quite different kinds of market failure can then emerge.

Our model assumes that potential entrants to the market are of two types: those with the technological knowledge to enter on the perimeter of the circle, and those who can instead

\footnotetext{
${ }^{1}$ Heal (1980) also uses the circle with centre geography, but in a quite different context. The (given) central firm is the sole producer of the good and the perimeter (retail) firms can buy from the centre and sell on to consumers. Consumers may buy from the perimeter or directly from the centre. Because of economies of scale in transportation provision via the perimeter may be socially optimal. The market outcome depends on the size of the market, with large markets tending to over-provide retail outlets, and vice versa for small.
} 
enter at the centre of the circle. We have in mind an application where the perimeter firms are geographically dispersed High Street shops (generating heterogeneous consumer transport costs of getting to the shops), and the central location is associated with mail-order provision or alternatively internet provision (where the cost of consumer access is plausibly homogeneous). In fact, for notational convenience but quite inessentially, we assume that there is just one potential central entrant. ${ }^{2}$ The sequence of entry decisions (again inessential) is that the potential central firm chooses to enter or not at stage one of the game (at entry cost $\mathrm{G}$ ), and perimeter entry decisions (at cost F per entrant) are at stage two, prior to pricing decisions by all entrants at stage three. The sequencing fits a scenario where the central firm is considering entry to a market served by High Street shops that can easily enter/exit the market (renting/ceasing to rent shop premises at cost F), while the central mail-order/internet provider must sink costs G (on warehouses, IT, catalogues,...). Of course other scenarios and timings are possible, but our main conclusions remain under the alternatives ${ }^{3}$.

The comparison between the market outcome (the subgame perfect equilibrium of the above three stage game) and the social optimum depends on the transport cost and entry cost parameters, and naturally we replicate the standard Salop result when G is sufficiently large so neither the market nor the social optimum would provide centrally. Elsewhere in the parameter space, some new and quite striking conclusions emerge, including the reversal of the standard Salop result, and the possibility that central provision might be forced out of the market even though all perimeter goods are of inferior quality in the vertical differentiation sense.

The remainder of the paper is organized as follows. Section 2 outlines the model, section 3 looks at social optima, section 4 at market equilibria and section 5 compares the two. Section 6 concludes.

\section{The model}

Our model presents the following features:

consumers are uniformly distributed on the perimeter of a circle of length equal to one with density equal to one; all consumers demand inelastically one unit of the good, i.e. it is assumed that the reservation price of all consumers, $V$, is very high;

- $\quad n$ firms locate symmetrically on the perimeter of the circle, while $c=0$ or 1 firms locate in the centre of the circle. All the $\mathrm{n}+\mathrm{c}$ firms sell the same good differentiated only by location. Let us assume that $\delta \geq 0$ is the transportation cost to buy from the centre ${ }^{4}$; consumers have to incur linear transportation costs to buy the good from a perimeter firm. The cost of transportation per unit of distance on the circle is $t$;

- $\quad$ n firms on the perimeter set prices $P_{i}, \mathrm{i}=1, \ldots, \mathrm{n}$;

- $\quad$ if c $=1$ the central firm's price is $P_{c}$;

- production marginal costs are constant and, without loss of generality, normalized to zero;

in order to enter the market, the $\mathrm{n}$ perimeter firms have to incur fixed costs equal to $F>0$; the central firm has, instead, to incur fixed costs $G>0$.

\footnotetext{
${ }^{2}$ As in Bouckaert (2000) and Balasubramanian (1998), because goods provided at the centre are homogeneous to consumers, the Bertrand paradox ensures that no more than one firm would want to locate at the centre.

3 A proof that the main results that follow are qualitatively not sensitive to the reversed entry sequencing can be found at http://www.socialsciences.manchester.ac.uk/economics/research/phd/mpezzino.htm.

${ }^{4}$ We are not necessarily assuming, then, that the distance from the perimeter to a central firm is equal to the radius of the circle. $\delta$ represents the transportation costs or the disutility, identical for all consumers, that everybody has to incur buying from the homogeneous firm.
} 
We want to study a three stage game in which, in stage one, $c=0$ or 1 firms decide to enter the market (incurring fixed costs $G$ ) and locate at the centre of the circle, in stage two $\mathrm{n}$ perimeter firms decide to enter the market, incurring fixed set up costs $F$, and locate (by assumption) symmetrically on the circumference of the circle. In the final stage of the game, the $\mathrm{n}+\mathrm{c}$ firms compete in prices à la Bertrand. We look for Subgame Perfect Nash Equilibria (SPNE) of this three-stage game as the market outcome (section 4) for comparison with the social optimum.

\section{Social optima}

A benevolent central planner must decide to set up either $c=0$ or $c=1$ central firms (given constant marginal costs of production $c>1$ will never be socially optimal) and a number $\mathrm{n}$ of (symmetrically located) perimeter firms. For sufficiently large $V(\geq G+\delta, F+t / 2)$ it will be socially optimal to provide one unit of the good to all consumers $(c=0, n=0$ will never be optimal), in which case social welfare maximisation requires minimisation of the total transport cost of getting consumers to goods. With $c=0$ and $\mathrm{n}$ perimeter firms the total transport cost is given by the standard Salop formula,

$$
S C(n)=t\left(n \frac{F}{t}+\frac{1}{4 n}\right) \text {. }
$$

If $c=1$ with $\mathrm{n}$ perimeter firms, a consumer located at distance y from the nearest perimeter firm would be optimally served by that firm rather than the central firm when $y \leq \delta / t$. If $\delta / t>1 / 2 n$ it follows that all consumers should be served by perimeter firms and the total transport cost is $G+S C(n)$. On the other hand if $\delta / t \leq 1 / 2 n$ it will be optimal for the central firm to serve consumers whose $y \in[\delta / t, 1 / 2 n]$, and the total transport cost of serving all consumers optimally is then

$$
2 n\left[\frac{1}{2} \frac{\delta^{2}}{t}+\left(\frac{1}{2 n}-\frac{\delta}{t}\right) \delta\right]=\delta-n \frac{\delta^{2}}{t} .
$$

We can now define precisely the planner's problem, where the feasible set is: $I=\{(c, n) \neq(0,0) \mid c=0$ or 1 and $n \in\{0,1,2, \ldots\}\}$.

\section{Definition 1}

A social optimum is $\left(c^{*}, n^{*}\right) \in I$ such that $T C\left(c^{*}, n^{*}\right) \leq T C(c, n)$ for all $(c, n) \in I$ where

$$
T C(c, n)= \begin{cases}S C(n) & \text { if } c=0, n>0 \\ G+\delta+n\left(F-\delta^{2} / t\right) & \text { if } c=1,0 \leq n \leq t / 2 \delta . \\ G+S C(n) & \text { if } c=1, n \geq t / 2 \delta\end{cases}
$$

We move to a continuous treatment of $\mathrm{n}$, as is usual in this literature on the Salop model. Since one clearly cannot do the same for c, we take care in Appendix B to address the discrete $\mathrm{n}$ case, and show that the results of the model are not affected by the continuous approximation.

\section{Definition 2}

A social optimum with continuous $\mathrm{n}$ is $c^{*}=0$ or 1 and $n^{*} \in \mathbb{R}_{+}$such that $T C\left(c^{*}, n^{*}\right) \leq T C(c, n)$ for all $(c, n) \in\left\{(c, n) \neq(0,0) \mid c=0\right.$ or 1 and $\left.n \in \mathbb{R}_{+}\right\}$, where $T C(c, n)$ is as defined in Definition 3.1. 
With continuous $\mathrm{n}$ the minimum of the (strictly convex) standard Salop $S C(n)$ occurs at $n^{*}=(\sqrt{t / F}) / 2$ with value $S C^{*}=\sqrt{F t}$. Obviously there can not be a social optimum with $c=1, n \geq t / 2 \delta$ since $G>0$. Thus the social optimum is either the above standard Salop result $\left(c^{*}=0, n^{*}=(\sqrt{t / F}) / 2\right)$ or at the minimum over $n \in[0, t / 2 \delta]$ of $G+\delta+n\left(F-\delta^{2} / t\right)$ with $\mathrm{c}=1$. If $F \leq \delta^{2} / t$ the latter minimum value is $G+\delta / 2+F t / 2 \delta$ ( $n=t / 2 \delta$ is then a minimum), but $S C(t / 2 \delta)=\delta / 2+F t / 2 \delta$ is smaller, so the social optimum is then the standard Salop; if $F>\delta^{2} / t$ the latter minimum value is $G+\delta$ ( $n=0$ is then the minimum) and standard Salop is again optimal if $G+\delta \geq S C^{*}$, whilst $c=1, n=0$ is optimal if $G+\delta \leq S C^{*}$. Defining $\varphi(F / t, \delta / t)=\sqrt{F / t}-\delta / t$, this proves:

\section{Theorem 1}

The social optima are:

(a) $c^{*}=0, n^{*}=\frac{1}{2} \sqrt{t / F}$ if either $F / t \leq(\delta / t)^{2}$ or if $F / t>(\delta / t)^{2}$ and $G / t \geq \varphi(F / t, \delta / t)$;

(b) $c^{*}=1, n^{*}=0$ if $F / t>(\delta / t)^{2}$ and $G / t \leq \varphi(F / t, \delta / t)$.

Figure 1 illustrates.

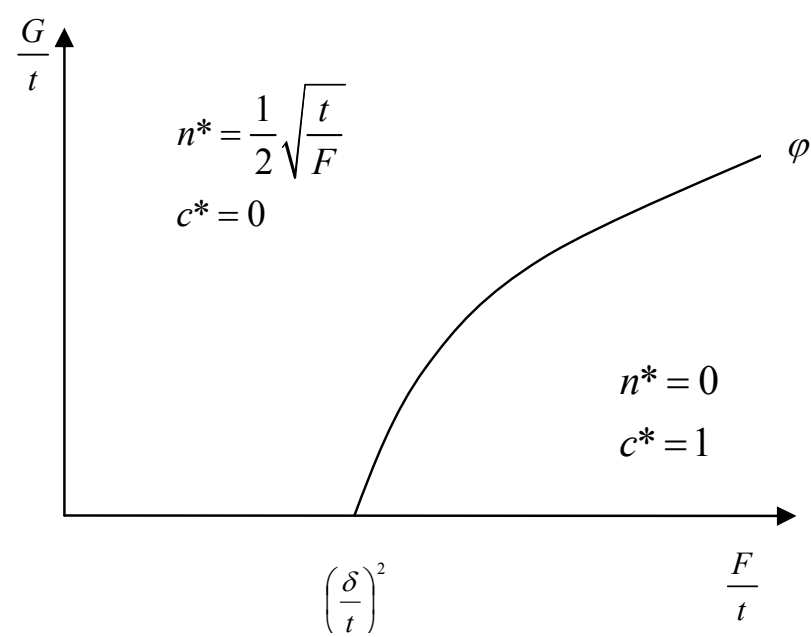

Figure 1: social optima.

The social optimum is dichotomous: the central planner prefers all consumers to be served either by the central firm or by the perimeter firms. The dichotomy of the social optimum does not depend on the assumption of linear transportation costs on the perimeter. In fact, for any strictly convex transportation cost function the optimal portion of the market that should be served by the generic perimeter firm i does not depend on $\mathrm{n}$, but only on $\delta / t$. As a result, the $\mathrm{TC}(1, \mathrm{n})$ is linear on $\mathrm{n}$ (when $n \leq t / 2 \delta$ ) and the dichotomy of the social optimum follows. Behind this is the symmetry of the locations. If it is worthwhile for the central planner to make use of both a perimeter firm and a central firm, it must be worthwhile to make use of all perimeter firms and the central firm.

\section{Market equilibrium}

Our ultimate interest is in how the market mechanism compares to the social optimum. We will compare the social optimum with market equilibrium: 


\section{Definition 3}

A market equilibrium is a subgame perfect Nash equilibrium of the following three stage game:

Stage one; $c=0$ or $c=1$ central firms enter the market, incurring fixed costs $G>0$.

Stage two; $n \in\{0,1,2, \ldots\}$ perimeter firms enter the market, each incurring fixed costs $F>0$.

Stage three; the $n+c$ entered firms choose prices simultaneously $\left(P_{i}, i=1, \ldots, n\right.$ for the perimeter firms, $P_{c}$ for the central firm when $c=1$ ) and meet the demands of consumers wishing to buy from them.

Our exposition will be abbreviated by assuming that the consumers' reservation price $V$ is sufficiently high that all consumers do buy one unit of the good in all subgames, and by restricting attention to market equilibrium where at least two perimeter firms enter. The backward induction derivation of such market equilibria thus starts with analysis of stage three price subgame equilibria when $c=0$ or 1 at stage one and $n \geq 2$ at stage two. When $c=0$, $n \geq 2$ a consumer at distance $\mathrm{x}$ form perimeter firm $i$ faces a full cost of $P_{i}+t x$ of buying from firm $i$ and comparison of these full costs over $i=1, \ldots, n$ leads to consumer demands and firm payoffs. Since $c=0$ we have the standard Salop scenario. Specification of demands and payoffs can be found in Tirole (1989), as well as derivation of the following subgame equilibrium, where $\Pi(0, n)$ denotes the (symmetric) profit of a perimeter firm.

\section{Lemma 1}

If $c=0$ and $n \geq 2$ the stage three subgame equilibrium prices and profits are $P_{i}=P=t / n, i=1, \ldots, n$ and $\Pi(0, n)=t / n^{2}$.

When $c=1, n \geq 2$ consumers can also buy from a central firm at full cost $P_{c}+\delta$. Comparisons of the full costs lead to demands, payoffs and the following subgame equilibria, where $\Pi_{c}(1, n)$ is the central firm profit and $\Pi(1, n)$ is the (again symmetric) perimeter firm profit.

\section{Lemma 2}

If $c=1$ and $n \geq 2$ the stage three subgame Nash equilibrium prices and profits are:

(i) Regime 1 ; if $n<t / \delta$ then

$$
\begin{aligned}
& P=\frac{t}{6 n}+\frac{\delta}{3}, P_{C}=\frac{t}{3 n}-\frac{\delta}{3} \\
& \Pi(1, n)=\frac{t}{18 n^{2}}\left(1+2 n \frac{\delta}{t}\right)^{2}, \Pi_{C}(1, n)=\frac{2 t}{9 n}\left(1-n \frac{\delta}{t}\right)^{2}
\end{aligned}
$$

(ii) Regime 2; if $t / \delta \leq n \leq 3 t / 2 \delta$ then

$$
\begin{aligned}
& P=\delta-\frac{t}{2 n}, P_{C}=0 \\
& \Pi(1, n)=\frac{\delta}{n}-\frac{t}{2 n^{2}}, \Pi_{C}(1, n)=0
\end{aligned}
$$

(iii) Regime 3; if $3 t / 2 \delta<n$ then 


$$
\begin{aligned}
& P=\frac{t}{n}, P_{C}=0 \\
& \Pi(1, n)=\frac{t}{n^{2}}, \Pi_{C}(1, n)=0
\end{aligned}
$$

\section{Proof}

See Appendix A.

There are now three types of subgame equilibrium. In regime 1 (small $n$ ), the central and perimeter firms obtain positive market share and profits. In regimes 2 and 3 all market share goes to perimeter firms; in regime 2 ( $n$ in a middle range) the presence of a central firm (although it ends up with zero market share offering to sell at marginal cost) restrains the price competition amongst perimeter firms, producing prices below the standard Salop level ${ }^{5}$, whilst this restraint disappears in regime 3 (large $n$ ) leading to standard Salop.

The stage two subgame equilibrium (after $c=0$ or 1 at stage one) will have $n(\geq 2)$ perimeter firms entering if each such firm will then earn a stage three profit (given by Lemmas 1 and 2) at least as large as the fixed cost $F$, and if entry of another perimeter firm reverses this inequality. Hence, from Lemmas 1 and 2:

\section{Lemma 3}

If $c=0$ then $n \geq 2$ perimeter firms will enter in the stage two subgame equilibrium if $t / n^{2} \geq F \geq t /(n+1)^{2}$.

\section{Lemma 4}

If $c=1$ then $n \geq 2$ perimeter firms will enter in the stage two subgame equilibrium if

$$
\begin{aligned}
& \frac{t}{18}\left(\frac{1}{n}+2 \frac{\delta}{t}\right)^{2} \geq F \geq \frac{t}{18}\left(\frac{1}{n+1}+2 \frac{\delta}{t}\right)^{2} \text { and } \frac{\delta}{t}<\frac{1}{n+1} \\
& \frac{t}{18}\left(\frac{1}{n}+2 \frac{\delta}{t}\right)^{2} \geq F \geq \frac{\delta}{n+1}-\frac{t}{2(n+1)^{2}} \text { and } \frac{1}{n+1} \leq \frac{\delta}{t} \leq \frac{1}{n} \\
& \frac{\delta}{n}-\frac{t}{2 n^{2}} \geq F \geq \frac{\delta}{n+1}-\frac{t}{2(n+1)^{2}} \quad \text { and } \quad \frac{1}{n} \leq \frac{\delta}{t} \leq \frac{3}{2(n+1)} \\
& \frac{\delta}{n}-\frac{t}{2 n^{2}} \geq F \geq \frac{t}{(n+1)^{2}} \quad \text { and } \quad \frac{3}{2(n+1)}<\frac{\delta}{t} \leq \frac{3}{2 n} \\
& \frac{t}{n^{2}} \geq F \geq \frac{t}{(n+1)^{2}} \quad \text { and } \quad \frac{3}{2 n}<\frac{\delta}{t}
\end{aligned}
$$

At this stage it is helpful to move to a "continuous n" format, as we did in the social optimum discussion and as is usually done in the literature regarding the Salop model ${ }^{6}$. For this the profit functions of Lemma $1(\Pi(0, n))$ and Lemma $2\left(\Pi(1, n), \Pi_{c}(1, n)\right)$ are seen as functions of $\mathrm{n}$ on the domain $[2, \infty)$ (instead of $\{2,3, \ldots\}$ ). It is easy to check that $\Pi(c, n)$ are then

\footnotetext{
${ }^{5}$ If $\mathrm{n}=1$ regime 3 would disappear. Focusing on the case $n \geq 2$ abbreviates our exposition without changing the results of the analysis.

${ }^{6}$ Again in Appendix B we show that the continuous approximation is legitimate and does not affect the results of the model.
} 
continuous, strictly decreasing functions of $\mathrm{n}$ for $c=0$ or 1 , and we take it that the number $n \in[2, \infty)$ of perimeter firms entering at stage two is that which solves the zero profit condition $\Pi(c, n)=F, c=0,1$.

Restricting attention to the parameter set

$$
S=\left\{(F / t, \delta / t) \mid \delta / t<1 / 2, \frac{1}{18}\left(\frac{1}{2}+2 \frac{\delta}{t}\right)^{2} \geq F / t>0\right\}
$$

such a number uniquely exists as follows:

(a) if $c=0, n=n_{0}=\sqrt{t / F}$ (the standard Salop number)

(b) if $c=1$,
(i) regime 1: $n=n_{11}=\left(3 \sqrt{\frac{2 F}{t}}-2 \frac{\delta}{t}\right)^{-1}$ if $F / t>\frac{1}{2}\left(\frac{\delta}{t}\right)^{2}$
(ii) regime 2: $n=n_{12}=\frac{1}{2 F}\left(\delta+\sqrt{\delta^{2}-t F}\right)$ if $\frac{1}{2}\left(\frac{\delta}{t}\right)^{2} \geq F / t \geq \frac{4}{9}\left(\frac{\delta}{t}\right)^{2}$
(iii) regime 3: $n=n_{13}\left(=n_{0}\right)=\sqrt{t / F}$ if $\frac{4}{9}\left(\frac{\delta}{t}\right)^{2}>F / t$.

Anticipating such numbers of perimeter entrants at stage two, the central firm decides at stage one to enter or not, giving the following analogue of subgame perfect equilibrium for the continuous $n$ case:

\section{Definition 4}

A market equilibrium with continuous $\mathrm{n}$ is either (a) or (b):

(a) $\quad c=0$ if $\Pi_{c}(1, n) \leq G$

(b) $\quad c=1$ if $\Pi_{c}(1, n) \geq G$

where, in each case, $\mathrm{n}$ is the (continuous) number of stage two entrants when $\mathrm{c}=1$, and $\Pi_{c}(1, n)$ is defined by Lemma 2 .

In (a) the central firm does not enter, as entry would lead to profits less than fixed costs; in (b) the central firm enters since it then makes a non-negative net profit, compared with 0 if it does not enter. The number of stage two entrants depends on parameters, as discussed earlier, which leads to:

\section{Theorem 2}

For parameters $(F / t, \delta / t) \in S$, the market equilibria are:

(a) $\quad c=0, n=n_{0}$ if $F / t \leq \frac{1}{2}(\delta / t)^{2}$ or if $F / t>\frac{1}{2}(\delta / t)^{2}$ and $G / t \geq \psi(F / t, \delta / t)$

(b) $\quad c=1, n=n_{11}$ if $F / t>\frac{1}{2}(\delta / t)^{2}$ and $G / t \leq \psi(F / t, \delta / t)$

where $\psi(F / t, \delta / t)=2 \frac{(\sqrt{2 F / t}-\delta / t)^{2}}{3 \sqrt{2 F / t}-2 \delta / t}$.

Proof

(a) If $c=0$ at stage one then $n=n_{0}$ in the stage two continuation. In $c=1$ at stage one and $F / t \leq(\delta / t)^{2} / 2$ then the stage two continuation is regime 2 or 3 and $\Pi_{c}=0$, so the central firm 
will not enter at stage one. If $\mathrm{c}=1$ and $F / t>(\delta / t)^{2} / 2$ then the stage two continuation is regime 1 and the central firm will not enter iff $\Pi_{c}=\Pi_{c}\left(1, n_{11}\right)=2 t\left(1-n_{11} \delta / t\right)^{2} / 9 n_{11} \leq G$ (substituting $\left.n_{11}=(3 \sqrt{2 F / t}-2 \delta / t)^{-1}\right)$ when holds iff $G / t \geq \psi(F / t, \delta / t)$.

(b) If $\mathrm{c}=1$ at stage one and $F / t>(\delta / t)^{2} / 2$ then the stage two continuation is regime 1 with $n=n_{11}$, and $\Pi_{c}=\Pi_{c}\left(1, n_{11}\right) \geq G$ (reversing the argument in (a)) iff $G / t \leq \psi(F / t, \delta / t)$. So the central firm does enter at stage one then. If $F / t \leq(\delta / t)^{2} / 2$, as in (a), the central firm does not enter. Q.E.D.

Figure 2 illustrates.

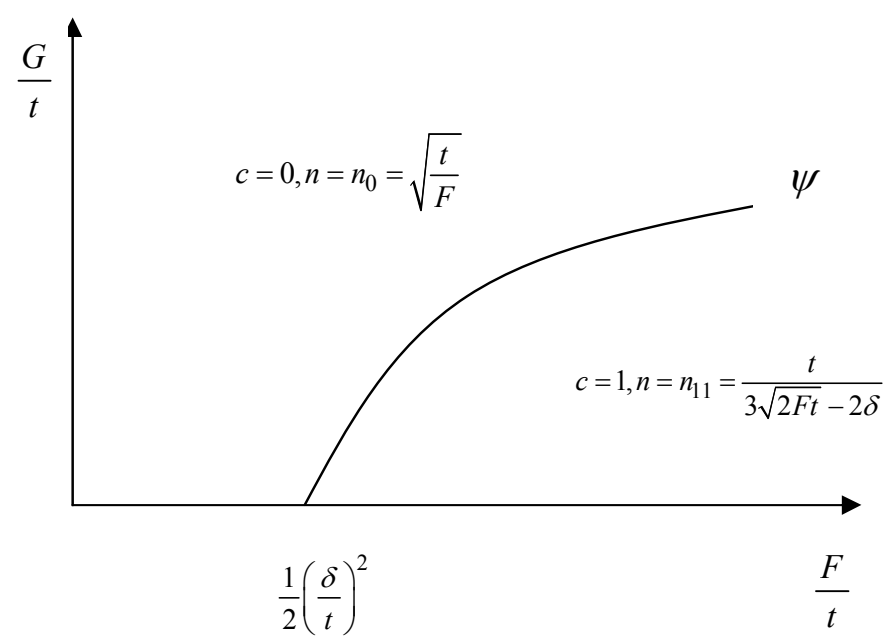

Figure 2: market equilibrium.

Not surprisingly, for high fixed costs for the central firm, no central provider would enter the market and the model replicates Salop standard results. For sufficiently low G and high F, instead, both types of firms survive in the market equilibrium.

\section{Comparisons}

We now compare the market equilibria and the social optima and present the main results of the paper.

First note that the curves $\varphi$ and $\psi$ in figure 1 and 2 intersect where $F / t=b=(3+2 \sqrt{2})(\delta / t)^{2}\left(\simeq 5.8(\delta / t)^{2}\right)$, and that this intersection lies in $\mathrm{S}$ only if $\delta / t<\Delta=(6 \sqrt{6+4 \sqrt{2}}-4)^{-1}(\simeq 0.06)$. We therefore focus on the parameter set

$$
\hat{S}=\{(F / t, \delta / t) \in S \mid \delta / t<\Delta\},
$$

in which case we have figure 3 , where the significance of $F / t=a$ is described later. 


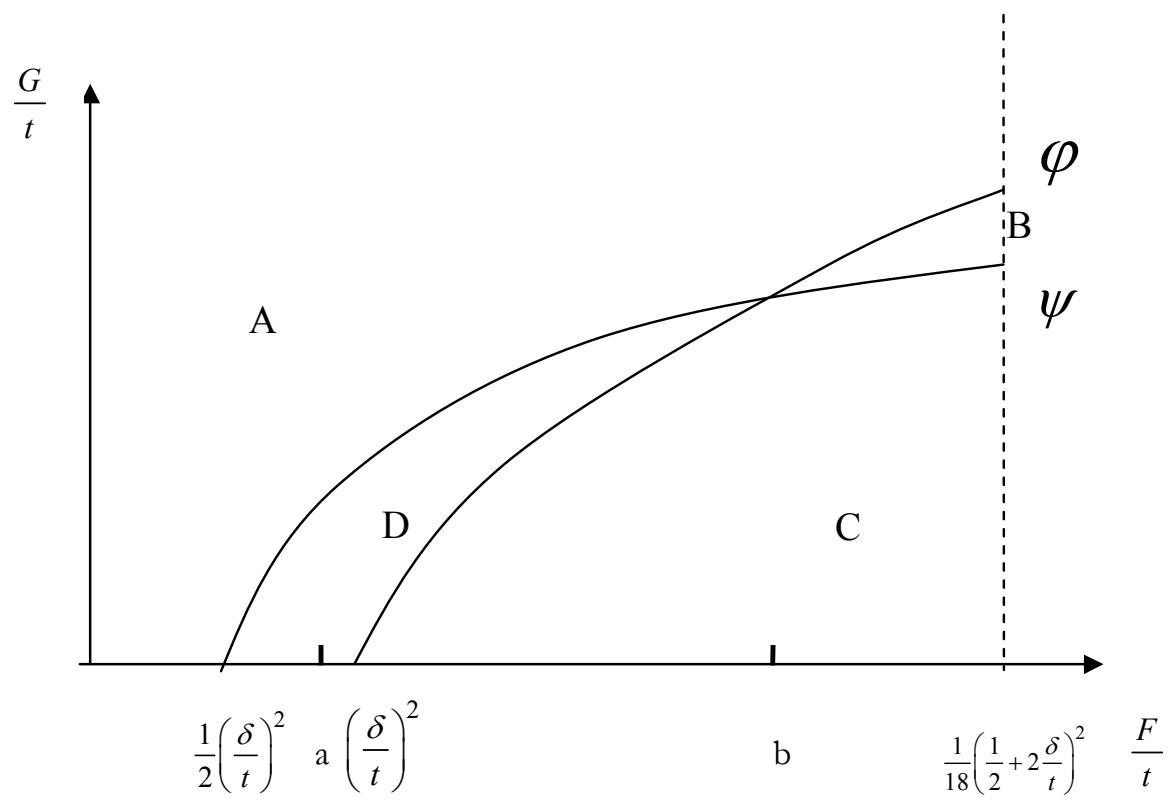

Figure 3: social optima and market equilibria.

The following propositions describe our main results.

\section{Proposition 1}

In region $A$ (where for any feasible $F, G$ is sufficiently high) there is no central firm in either the market equilibrium or the social optimum, and the number of perimeter firms in the market equilibrium is excessive (standard Salop) compared to the social optimum.

As we mentioned above, for fixed costs belonging to region A the model replicates the standard Salop result.

\section{Proposition 2}

In region $B$ (where $F$ is sufficiently high and $G$ is in an intermediate range) the social optimum requires provision only by the central firm, but the market equilibrium involves provision only by perimeter firms.

In region B the excessive number of differentiated products provided by the market forces out all central provision, which from the social viewpoint should be the only source. From this point of view, the Salop result is generated once again, but in a most extreme form.

\section{Proposition 3}

In region $C$ (where $F$ is sufficiently high and $G$ is sufficiently low) there is a central firm in both the market equilibrium and the social optimum; however the social optimum involves provision solely by the central firm, while the market equilibrium involves provision by both types of firms.

The market failure generated in region $\mathrm{C}$ is in a sense milder than the one generated in region B. The market mechanism does induce central provision, but also product differentiation with $n_{11}$ perimeter firms. Reminiscent of the standard Salop result, the market fails by producing too many differentiated products, but now the optimal number is zero. 


\section{Proposition 4}

In region $D$ (where $F$ is in an intermediate range and $G$ is sufficiently low) the market equilibrium presents both types of firms but the social optimum involves provision only by perimeter firms. For $F$ sufficiently high, i.e. $F / t>a, a=4(\delta / t)^{2} /(3 \sqrt{2}-2)^{2}$, the market equilibrium produces an insufficient number of perimeter firms compared to the social optimum.

In region $\mathrm{D}$ the market mechanism induces the central firm to enter in competition with the perimeter firms. The effect is to reduce the number of perimeter firms from $\sqrt{t / F}$ to $n_{11}$ $(<\sqrt{t / F}$ in region $\mathrm{D})$. Indeed, for $\mathrm{F} / \mathrm{t}$ sufficiently large in this region, the effect is to reduce the number of perimeter firms to below the socially optimal number $\left(n_{11}<(\sqrt{t / F}) / 2\right)$. Thus, in a sense reversing the standard Salop result, the presence of the central firm here induces the market to provide too few differentiated products.

It is interesting to note that the homogeneous good would be vertically differentiated from and of lower quality than all possible differentiations if $V-t / 2 \geq V-\delta$ or $\delta / t \geq 1 / 2$, a possibility excluded from our discussion. On the other hand in the limit where $\delta=0$ the homogenous central good dominates in the vertical differentiation sense all differentiated products. In this limit, region $\mathrm{D}$ disappears, but $\mathrm{A}, \mathrm{B}$ and $\mathrm{C}$ survive, and perhaps the most striking of our market failures then occurs in region B. Here the market mechanism induces the provision of a variety of horizontally differentiated goods which are of uniformly inferior quality (in the vertical differentiation sense) to the homogenous good, which is not provided at all by the market although it would be the only good provided in the social optimum. And in all cases in this limit (A, B and C) market provision of the differentiated products is excessive.

\section{Proposition 5}

If $\delta=0$, region $D$ disappears, and the good provided by the central firm is of superior quality (in the vertical differentiation sense) to all goods provided by perimeter firms. At all such parameters, the equilibrium number of perimeter firms is excessive as in region $A$ (proposition 1) or region B (proposition 2) or region $C$ (proposition 3).

Whilst $\delta=0$ is an idealisation of any real scenario, it is probably the cases where $\delta$ is relatively small that provides relevant lessons for our example of internet/mail order shopping (centre) versus High Street shopping (perimeter), since for many nowadays internet access and ordering by mail is a very low cost activity compared to a High Street shopping excursion. It follows that the broad lesson from our analysis is that the nature of the competition between internet/mail order and High Street shops favours the High Street, in the sense that the market allows the survival of an excessive number of such shops compared to the social optimum, and works against the internet/mail order possibly precluding such provision completely when it should be the only source of the commodity, and when it is of uniformly higher quality than any High Street alternative.

As we said before, reversing the entry sequencing does not affect the main results of the paper. In fact, regions A, B, C in figure 3 are generated again under the alternative entry sequencing. For parameters belonging to Region D, the model could generate multiple equilibria yielding either the reversed Salop result once again or no entry for the central firm and the replication of the standard Salop result. For $\delta=0$, region D disappears under all entry sequencing, producing identical results no matter the timing chosen.

\footnotetext{
${ }^{7}$ See footnote 3 .
} 


\section{Conclusions}

In the geography of a Salop circle with centre, where firms providing horizontally differentiated goods locate around the perimeter of the circle and a firm providing a homogenous good may locate at the centre of the circle, we have studied and compared the social optima and the market equilibria, the latter as the subgame perfect equilibria of an entry-pricing game. In the limit where the cost of consumer access to the central firm is zero the nature of the market failure is particularly striking. In this case the good provided by the central firm is vertically differentiated and of superior quality to all goods provided on the perimeter. But the market always produces too much product differentiation, and sometimes it leads to provision only by perimeter firms when (from the social point of view) the central firm should be the sole provider.

We have suggested an application to competition between internet/mail order (centre) and High Street (perimeter) shops, in which case the ease of internet/mail order shopping access suggests that the limiting case of the above paragraph may be a reasonable approximation. In this context our results suggest that the market mechanism favours the High Street, always producing too many High Street shops, and sometimes forestalling internet/mail order provision when this should be the only form of provision.

When the cost of consumer access to the central firm is non-zero a further possibility emerges, namely the central firm enters the market when it should not, reducing the number of perimeter firms possibly to a level which is below the socially optimal number. This last possibility reverses the excessive market provision of product differentiation in the standard Salop model (where there is no central firm possibility), whilst the earlier possibilities produce more extreme versions of the standard Salop market failure.

\section{References}

Anderson and De Palma (2000): "From Local to Global Competition", European Economic Review, 44, 423-448.

Balasubramanian (1998): "Mail Versus Mall: A Strategic Analysis of Competition between Direct Marketers and Conventional Retailers," Marketing Science, 17, 181-195.

Bouckaert (2000): "Monopolistic Competition with a Mail Order Business," Economics Letters, 66, 303-310.

Cheng and Nault (2006): "Internet Channel Entry: Retail Coverage and Entry Cost Advantage", ITM Special Issue

Dixit and Stiglitz (1977): "Monopolistic Competition and Optimum Product Diversity", American Economic Review, 67, 297-308

Heal (1980): "Spatial Structure in the Retail Trade: A Study in Product Differentiation with Increasing Returns," The Bell Journal of Economics, 11, 565-583.

Salop (1979): "Monopolistic Competition with Outside Goods," The Bell Journal of Economics, 10, 141-156.

Tirole, J. (1988): "The Theory of Industrial Organization", MIT Press, Massachusetts. 


\section{Appendices}

\section{A. Proof of Lemma 2}

(i) With $P, P_{c}$ as in the statement, $P+t x=P_{c}+\delta \Rightarrow x=\left(P_{c}-P+\delta\right) t=1 / 6 n+\delta / 3 t \in(0,1 / 2 n)$ since $n<t / \delta$. Thus $2 \mathrm{x}$ would be the equilibrium market share of each perimeter firm, with $1-2 \mathrm{nx}$ for the central firm (the central firm takes the middle sections of each perimeter segment between two adjacent perimeter firms, the perimeter firm taking the end sections nearest to them). The formulae for the (positive) equilibrium profits follow. We now show that $P, P_{c}$ have the required Nash properties.

Consider the best response choice of $P_{c}$ against $P_{i}=P=t / 6 n+\delta / 3, i=1, \ldots, n$. As long as $(1-2 n x) \in[0,1]$ or $P_{c} \in[t / 6 n-2 \delta / 3,2 t / 3 n-2 \delta / 3]$ the central firm continues to get a market share $(1-2 n x)$, so $\Pi_{c}=P_{c}(1-2 n x)=P_{c}\left[1-2 n\left(P_{c}-P+\delta\right) / t\right]$ which is strictly concave in $P_{c}$ which stationary point $P_{c}=(P-\delta+t / 2 n) / 2=t / 3 n-\delta / 3$. If $P_{c}>2 t / 3 n-2 \delta / 3$, the central firm's market share is zero, which cannot be a best response. If $P_{c}<t / 6 n-2 \delta / 3$, the central firm's market share is always 1 , so such $P_{c}$ also cannot be a best response. Thus $P_{c}=t / 3 n-\delta / 3$ is the central firm's best response when $P_{i}=P=t / 6 n+\delta / 3, i=1, \ldots, n$. Now consider the best response of $P_{i}$ against $P_{c}=t / 3 n-\delta / 3$ and $P_{j}=t / 6 n+\delta / 3, j \neq i$. Firm i's market share will be $2 x_{i}$ where $x_{i}=\left(P_{c}-P_{i}+\delta\right) / t$ if $x_{i} \in[0,1 / n-x]$, or if $P_{i} \in[\delta-t / 2 n, t / 3 n+2 \delta / 3]$, so $\Pi_{i}=2 P_{i} x_{i}$ which is strictly concave in $P_{i}$ with stationary point $P_{i}=\left(P_{c}+\delta\right) / 2=P=t / 6 n+\delta / 3$. If $P_{i}>t / 3 n+2 \delta / 3$ then i's market share is zero which cannot be a best response. If $P_{i} \in[\delta / 3-5 t / 6 n, \delta-t / 2 n]$ then the central firm receives no market share from perimeter segments between $\mathrm{i}$ and $\mathrm{i}+1$ and between i and i- 1 . Thus i's market share is $2 \tilde{x}_{i}$ where $\tilde{x}_{i}=1 / 2 n+\left(P-P_{i}\right) / 2 t$, so $\Pi_{i}=2 P_{i} \tilde{x}_{i}$ which is strictly concave in $P_{i}$ with $\partial \Pi_{i} / \partial P_{i}=1 / n+\left(P-2 P_{i}\right) / t=13 / 6 n-5 \delta / 3 t>0$ at $P_{i}=\delta-t / 2 n$, which ensures that there cannot be a best response with $P_{i} \in[\delta / 3-5 t / 6 n, \delta-t / 2 n]$. Since $\delta / 3-5 t / 6 n<0$ when $n<t / \delta$, there also cannot be a best response with $P_{i} \leq \delta / 3-5 t / 6 n$, thus ensuring that each perimeter firm's best response $P_{i}$ to $P_{c}=t / 3 n-\delta / 3$ and $P_{j}=t / 6 n+\delta / 3, j \neq i$ is , completing the proof of (i).

(ii) With $P, P_{c}$ as in the statement, $P_{c}+\delta=P+t / 2 n=\delta$, so a consumer located at the midpoint of a perimeter segment between firms $i$ and $i+1$ is indifferent between buying from $i, i+1$ or the central firm, all consumers in the segment nearer to $i(i+1)$ strictly preferring to buy from $i$ $(i+1)$. The central firm gets no market share and zero profits, with each perimeter firm serving $1 / n$ of the market leading to the claimed (positive) profits.

Given that $P_{i}=P, i=1, \ldots, n$, it is clear that $P_{c}=0$ is a best response for the central firm - raising $P_{c}$ will still leave it without market share and lowering $P_{c}$ can only lead to losses.

Consider the best response $P_{i}$ for perimeter firm i when $P_{c}=0$ and $P_{j}=P=\delta-t / 2 n, j \neq i$. If $P_{i} \in[\delta-t / 2 n, \delta]$ then i's market share is $2 x_{i}$ where $x_{i}=\left(P_{c}-P_{i}+\delta\right) / t=\left(\delta-P_{i}\right) / t$ (the central firm gets positive market share when $\left.P_{i}<\delta-t / 2 n\right)$, so $\Pi_{i}=2 P_{i} x_{i}$ which is strictly concave in $P_{i}$ and $\partial \Pi_{i} / \partial P_{i}=2 \delta / t-4 P_{i} / t=2(1 / n-\delta / t) \leq 0$ at $P_{i}=\delta-t / 2 n$. Thus there is no benefit from raising $P_{i}$ from $\delta-t / 2 n$ in this range, and choosing $P_{i}>\delta$ produces zero market share and also cannot improve on $P_{i}=\delta-t / 2 n$. If $P_{i} \in[\delta-3 t / 2 n, \delta-t / 2 n]$ then i's market share is $2 \tilde{x}_{i}$ where $\tilde{x}_{i}=1 / 2 n+\left(P-P_{i}\right) / 2 t$ and, as in proof (i), $\Pi_{i}=2 P_{i} \tilde{x}_{i}$ is strictly concave in $P_{i}$ with $\partial \Pi_{i} / \partial P_{i}=1 / n+\left(P-2 P_{i}\right) t \geq 0$ when $P_{i}=P=\delta-t / 2 n$. Hence there is no benefit for $\mathrm{i}$ in lowering price from $\delta-t / 2 n$ in this range and there is certainly no benefit from lowering price below $\delta-3 t / 2 n \leq 0$. Thus $P_{i}=\delta-t / 2 n$ is a best response for $\mathrm{i}$ when $P_{c}=0$ and $P_{j}=\delta-t / 2 n, j \neq i$, completing the proof of (ii). 
(iii) With $P, P_{c}$ as in the statement, $P_{c}+\delta>P+t / 2 n$ since $\delta>3 t / 2 n$, so the midpoint consumer (as in the proof of (ii)) is indifferent between buying from i and $\mathrm{i}+1$, but both are now strictly preferred to buying from the central firm. Consumers nearer to $i(i+1)$ buy from $i(i+1)$ giving each perimeter firm a market share of $1 / \mathrm{n}$ and the claimed (positive) profits. The central firm again gets zero market share and profits.

Clearly (similar to proof of (ii)) $P_{c}=0$ is a best response for the central firm if $P_{i}=t / n, i=1, \ldots, n$.

Consider the best response for perimeter firm i if $P_{c}=0$ and $P_{j}=P=t / n, j \neq i$. If $P_{i} \in[0,2 \delta-2 t / n]$ then i's market share is $2 \tilde{x}_{i}$ where $\tilde{x}_{i}=1 / 2 n+\left(P-P_{i}\right) / 2 t$ and $\Pi_{i}=P_{i} 2 \tilde{x}_{i}$ is strictly concave in $P_{i}$ with stationary point $P_{i}=t / n$ when $P=t / n$. Obviously $P_{i}<0$ cannot improve on this. Suppose $P_{i} \in[2 \delta-2 t / n, \delta]$. The central firm gets positive market share when $P_{i}>\delta$ and i's market share in this range is $2 x_{i}$ where $x_{i}=\left(P_{c}-P_{i}+\delta\right) / t=\left(\delta-P_{i}\right) / t$. As in the proof of (ii), the resulting $\Pi_{i}$ is strictly concave in $P_{i}$ with $\partial \Pi_{i} / \partial P_{i}=2 \delta / t-4 P_{i} / t=8 / n-6 \delta / t$ when $P_{i}=2 \delta-2 t / n$, so $P_{i}$ in this range also cannot improve on $P_{i}=t / n$, and similarly for $P_{i} \geq \delta$ which produces zero market share and profits for i, completing the proof of (iii). Q.E.D.

\section{B. Discrete analysis}

This appendix shows that there exist functions $\hat{\varphi}(F / t, \delta / t), \hat{\hat{\psi}}(F / t, \delta / t)$ such that, restricting attention to parameters $(F / t, \delta / t) \in \hat{S}, \hat{\varphi}>\varphi, \hat{\hat{\psi}} \geq \psi$ and the regions indicated $\hat{A}, \hat{B}, \hat{C}$ and $\hat{D}$ in figure 4 are nonempty.

Moreover as $\delta / t \rightarrow 0$, region $\hat{D}$ disappears but $\hat{A}, \hat{B}, \hat{C}$ remain nonempty. The point is that, qualitatively, conclusions about comparisons between social optima and market equilibria in the discrete setting are the same in regions $\hat{A}, \hat{B}, \hat{C}$ and $\hat{D}$ as in their continuous counterparts (A, B, C, D in figure 3). Thus the conclusions reached earlier in the text about the nature of market failure in the model do not depend on the continuous approximation. 


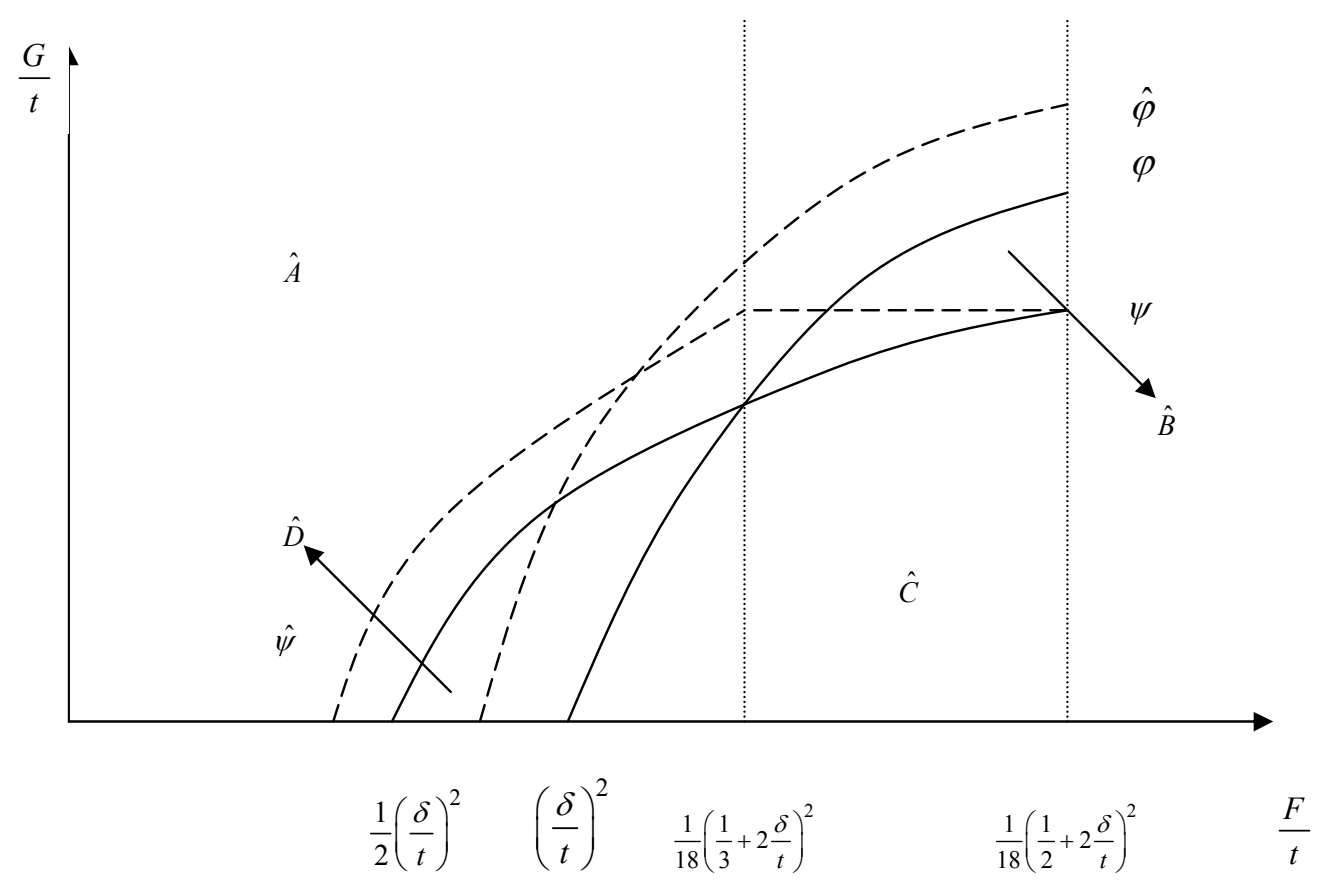

Figure 4: social optima and market equilibria with discrete $n$.

\section{B.1. Discrete social optima}

\section{Lemma B.1.}

If $\hat{S}=\{(F / t, \delta / t) \in S \mid \delta / t<\Delta\}$, sufficient condition for $\mathrm{c}=0$ in the social optimum when $\mathrm{n}$ is a discrete variable is given by $G / t \geq \hat{\varphi}(F / t, \delta / t)$, where

$n_{a}=((\sqrt{t / F}) / 2)-1$ and $\hat{\varphi}(F / t, \delta / t)= \begin{cases}\frac{F}{t} n_{a}+\frac{1}{4 n_{a}}-\frac{\delta}{t} & \text { if } \frac{F}{t} \geq\left(\frac{\delta}{t}\right)^{2} \\ n_{a}\left(\frac{\delta}{t}\right)^{2}+\frac{1}{4 n_{a}}-\frac{\delta}{t} & \text { if } \frac{F}{t}<\left(\frac{\delta}{t}\right)^{2}\end{cases}$

In this case, the socially optimal discrete number of perimeter firms is an integer $\hat{n} \in\left(n_{a}, n_{b}\right)$, $n_{b}=((\sqrt{t / F}) / 2)+1$.

Proof

If $\mathrm{n}$ is a discrete variable the solution for the minimization of $S C(n)$ will lie in $\hat{n} \in[(\sqrt{t / F}) / 2-1,(\sqrt{t / F}) / 2+1]=\left[n_{a}, n_{b}\right]$. Note that $S C\left(n_{a}\right)>S C\left(n_{b}\right)$ in $\hat{S}=\{(F / t, \delta / t) \in S \mid \delta / t<\Delta\}$.

If $F / t \geq(\delta / t)^{2}, T C(1, n)$ is minimized at $\mathrm{n}=0$ and $T C(1,0)=G+\delta$. Thus, a sufficient condition for $\mathrm{c}=0$ and $\hat{n}$ to be the social optimum is

$T C(1,0) \geq S C\left(n_{a}\right) \Rightarrow \frac{G}{t} \geq n_{a} \frac{F}{t}+\frac{1}{4 n_{a}}-\frac{\delta}{t}=\frac{F}{t}\left(\frac{1}{2} \sqrt{\frac{t}{F}}-1\right)+\frac{1}{2 \sqrt{\frac{t}{F}}-4}-\frac{\delta}{t}=\hat{\varphi}\left(\frac{F}{t}, \frac{\delta}{t}\right)$ if $\quad \frac{F}{t} \geq\left(\frac{\delta}{t}\right)^{2}$. 
If $F / t<(\delta / t)^{2}$ a sufficient condition for $\mathrm{c}=0$ to be the social optimum when $\mathrm{n}$ is a discrete variable is

$T C\left(1, n_{a}\right) \geq S C\left(n_{a}\right) \Rightarrow \frac{G}{t} \geq n_{a}\left(\frac{\delta}{t}\right)^{2}+\frac{1}{4 n_{a}}-\frac{\delta}{t}=\left(\frac{1}{2} \sqrt{\frac{t}{F}}-1\right)\left(\frac{\delta}{t}\right)^{2}+\frac{1}{2 \sqrt{\frac{t}{F}}-4}-\frac{\delta}{t}=\hat{\varphi}\left(\frac{F}{t}, \frac{\delta}{t}\right)$ if $\frac{F}{t}<\left(\frac{\delta}{t}\right)^{2}$.

Q.E.D.

Note that $\hat{\varphi}(F / t, \delta / t)$ is continuous, strictly positive when $F / t=(\delta / t)^{2}$, equal to zero when $F / t=((\delta / t) /(1+2 \delta / t))^{2} \quad\left(>(\delta / t)^{2} / 2 \quad\right.$ for $\left.\delta / t \in\left[0, d_{1}\right] \quad\right) \quad$ and increasing in $F / t$ and $\hat{\varphi}(F / t, \delta / t)>\varphi(F / t, \delta / t)$ for $(F / t, \delta / t) \in \hat{S}$.

\section{Lemma B.2.}

If $\hat{S}=\{(F / t, \delta / t) \in S \mid \delta / t<\Delta\}$, sufficient conditions for $\mathrm{c}=1$ and $\mathrm{n}=0$ to be the social optimum when $\mathrm{n}$ is a discrete variable are $G / t \leq \varphi(F / t, \delta / t)$ and $F / t \geq(\delta / t)^{2}$.

Proof

If $F / t \geq(\delta / t)^{2}$ then $T C(1, n)$ is minimised at $\mathrm{n}=0$ and $T C(1,0)=G+\delta$. If $\mathrm{c}=0 \quad S C(\hat{n}) \geq \sqrt{F t}$, therefore $\mathrm{c}=1$ and $\mathrm{n}=0$ is the social optimum if

$T C(1,0) \leq \sqrt{F t} \Rightarrow \frac{G}{t} \leq \sqrt{\frac{F}{t}}-\frac{\delta}{t}=\varphi\left(\frac{F}{t}, \frac{\delta}{t}\right) \cdot$ Q.E.D.

\section{B.2. Discrete market equilibrium}

\section{$\underline{\text { Lemma B.3 }}$}

If $\hat{S}=\{(F / t, \delta / t) \in S \mid \delta / t<\Delta\}$, sufficient conditions for $\mathrm{c}=1$ and the unique integer $n \in\left(n_{11}-1, n_{11}\right]$ to be a SPNE are:

$\frac{G}{t} \leq \psi\left(\frac{F}{t}, \frac{\delta}{t}\right)$ and $\frac{F}{t} \geq \frac{1}{2}\left(\frac{\delta}{t}\right)^{2}$.

Proof

Lemma 4 describes the perimeter entry stage when $\mathrm{n}$ is treated as a discrete variable. Sufficient conditions for (4) in lemma 4 are that $F / t \geq(3 \delta / t)^{2} / 18=(\delta / t)^{2} / 2$ and $\Pi_{c}\left(1, n_{11}\right) \geq G \Rightarrow G / t \leq \psi(F / t, \delta / t)$, since it follows that $n \leq t / \delta$ (regime 1$)$ and $\Pi_{c}(1, n) \geq \Pi_{c}\left(1, n_{11}\right)$. Q.E.D.

\section{Lemma B.4}

If $\hat{S}=\{(F / t, \delta / t) \in S \mid \delta / t<\Delta\}$, sufficient conditions for $\mathrm{c}=0$ and the unique $n \in(\sqrt{t / F}-1, \sqrt{t / F}]$ to be a SPNE are:

(i) $\frac{F}{t} \leq \frac{1}{2}\left(\frac{\frac{\delta}{t}+\frac{2}{3}\left(\frac{\delta}{t}\right)^{2}}{1+\frac{\delta}{t}}\right)^{2}$ 
(ii) $\frac{F}{t}>\frac{1}{2}\left(\frac{\frac{\delta}{t}+\frac{2}{3}\left(\frac{\delta}{t}\right)^{2}}{1+\frac{\delta}{t}}\right)^{2}$ and $\left.\frac{G}{t} \geq \frac{2}{9\left(\frac{1}{3 \sqrt{\frac{2 F}{t}}-2 \frac{\delta}{t}}-1\right.}\right)\left[1-\left(\frac{1}{3 \sqrt{\frac{2 F}{t}-2 \frac{\delta}{t}}-1}\right) \frac{\delta}{t}\right]^{2}=\hat{\psi}(F / t, \delta / t)$.

Proof

Sufficient conditions for $\mathrm{c}=1$ to be unprofitable for the central firm are:

(i) $\max \left(2, n_{11}-1\right) \geq t / \delta$, ensuring that the price competition generates regimes 2 or 3 ;

(ii) $\max \left(2, n_{11}-1\right)<t / \delta$, ensuring that the price competition generates regime 1 , and $\Pi_{c}\left(1, n_{11}-1\right) \leq G$.

(i) requires then that $n_{11}-1 \geq t / \delta \Rightarrow \frac{F}{t} \leq \frac{1}{2}\left(\frac{\frac{\delta}{t}+\frac{2}{3}\left(\frac{\delta}{t}\right)^{2}}{1+\frac{\delta}{t}}\right)^{2}$, while (ii) requires that $\Pi_{c}\left(1, n_{11}-1\right) \leq G \Rightarrow \frac{G}{t} \geq \hat{\psi}(F / t, \delta / t)$. Q.E.D.

Note that $\hat{\psi}(F / t, \delta / t)$ is a first approximation of a discrete version of $\psi(F / t, \delta / t)$. Note in addition that $\hat{\psi}(F / t, \delta / t)$ is continuous, strictly positive when $F / t=(\delta / t)^{2} / 2$, equal to zero when $F / t=\left(\left(\delta / t+2(\delta / t)^{2} / 3\right) /(1+\delta / t)\right)^{2} \quad\left(<(\delta / t)^{2} / 2\right)$ and increasing in $F / t$, and $\hat{\psi}(F / t, \delta / t)>\psi(F / t, \delta / t)$ for $\delta / t \in[0, \Delta]$.

Unfortunately, the condition represented by $\hat{\psi}(F / t, \delta / t)$ does not ensure that $\hat{B}$ in figure 4 is a nonempty set. A less approximate sufficient condition for $\mathrm{c}=0$ and $n \in[\sqrt{t / F}-1, \sqrt{t / F}]$ to be a SPNE is showed in lemma B.5.

\section{$\underline{\text { Lemma B.5 }}$}

If $\hat{S}=\{(F / t, \delta / t) \in S \mid \delta / t<\Delta\}$, sufficient condition for $\mathrm{c}=0$ and the unique $n \in(\sqrt{t / F}-1, \sqrt{t / F}]$ to be a SPNE is given by:

(i) $\frac{F}{t} \leq \frac{1}{2}\left(\frac{\frac{\delta}{t}+\frac{2}{3}\left(\frac{\delta}{t}\right)^{2}}{1+\frac{\delta}{t}}\right)^{2}$

(ii) $\frac{F}{t}>\frac{1}{2}\left(\frac{\frac{\delta}{t}+\frac{2}{3}\left(\frac{\delta}{t}\right)^{2}}{1+\frac{\delta}{t}}\right)^{2}$ and $\hat{\hat{\psi}}=\left\{\begin{array}{ll}\hat{\psi}(F / t, \delta / t) & \text { if } \frac{1}{2}\left(\frac{\frac{\delta}{t}+\frac{2}{3}\left(\frac{\delta}{t}\right)^{2}}{1+\frac{\delta}{t}}\right)^{2} \geq \frac{F}{t} \geq \frac{1}{18}\left(\frac{1}{3}+2 \frac{\delta}{t}\right)^{2} \\ \frac{1}{9}\left(1-2 \frac{\delta}{t}\right)^{2} & \text { if } \frac{1}{18}\left(\frac{1}{3}+2 \frac{\delta}{t}\right)^{2}>\frac{F}{t} \geq \frac{1}{18}\left(\frac{1}{2}+2 \frac{\delta}{t}\right)^{2}\end{array}\right.$.

Proof 
When $\frac{1}{18}\left(\frac{1}{3}+2 \frac{\delta}{t}\right)^{2}>\frac{F}{t} \geq \frac{1}{18}\left(\frac{1}{2}+2 \frac{\delta}{t}\right)^{2}$, as shown by lemma 4, (4), if the central firm enters in stage one the number of perimeter firms that will enter the market will be equal to 2 . When $\mathrm{n}=2$, the profits of the central firm are given by lemma 2 and are non positive if $G \geq \frac{t}{9}\left(1-2 \frac{\delta}{t}\right)^{2} \Rightarrow \frac{G}{t} \geq \frac{1}{9}\left(1-2 \frac{\delta}{t}\right)^{2}=\hat{\hat{\psi}}\left(\frac{F}{t}, \frac{\delta}{t}\right)$. So, when $\frac{1}{18}\left(\frac{1}{3}+2 \frac{\delta}{t}\right)^{2}>\frac{F}{t} \geq \frac{1}{18}\left(\frac{1}{2}+2 \frac{\delta}{t}\right)^{2}$, the $\hat{\hat{\psi}}(F / t, \delta / t)$ represents a more precise (sufficient) condition for $\mathrm{c}=0$ and $n \in[\sqrt{t / F}-1, \sqrt{t / F}]$ to be a SPNE than $\hat{\psi}(F / t, \delta / t)$. Q.E.D.

Note that

$$
\begin{aligned}
& \hat{\hat{\psi}}(F / t, \delta / t) \geq \psi(F / t, \delta / t), \\
& \hat{\hat{\psi}}\left(F / t=(1 / 2+2 \delta / t)^{2} / 18, \delta / t\right)=\psi\left(F / t=(1 / 2+2 \delta / t)^{2} / 18, \delta / t\right) \\
& \hat{\hat{\psi}}\left(F / t=(1 / 2+2 \delta / t)^{2} / 18, \delta / t\right)<\hat{\psi}\left(F / t=(1 / 2+2 \delta / t)^{2} / 18, \delta / t\right) \\
& \hat{\hat{\psi}}\left(F / t=(1 / 3+2 \delta / t)^{2} / 18, \delta / t\right)>\hat{\psi}\left(F / t=(1 / 3+2 \delta / t)^{2} / 18, \delta / t\right) \text { for } \\
& (F / t, \delta / t) \in \hat{\hat{S}}=\{(F / t, \delta / t) \in \hat{S} \mid \delta / t<\hat{\Delta}\} .
\end{aligned}
$$

\section{Proposition B1}

If $\varphi, \hat{\varphi}, \psi, \hat{\hat{\psi}}$ are defined on $(F / t, \delta / t) \in \hat{S}$, then $\hat{\varphi}>\varphi, \hat{\psi}>\psi, \hat{\hat{\psi}} \geq \psi$ and regions $\hat{A}, \hat{B}, \hat{C}$ and $\hat{D}$ in figure 4 are nonempty and present the same properties as the respective regions $\mathrm{A}, \mathrm{B}, \mathrm{C}$ and $\mathrm{D}$ in figure 3.

\section{Proof}

$\hat{\varphi}>\varphi, \hat{\psi}>\psi, \hat{\hat{\psi}} \geq \psi$ are satisfied by lemmas B.1-B.5.

$\hat{A}=\{(F / t, \delta / t) \in \hat{S} \mid G / t \geq \max [0, \hat{\varphi}, \hat{\hat{\psi}}]\}$ and it is clearly nonempty. For $(F / t, \delta / t) \in \hat{A}$ the social optimum is $c=0, n=\hat{n}$ and the market equilibrium is $c=0, n \in[\sqrt{t / F}-1, \sqrt{t / F}+1]$. A sufficient condition for the long run number of perimeter firm to be greater than the socially optimal one is

$\sqrt{\frac{t}{F}}-1 \geq \frac{1}{2} \sqrt{\frac{t}{F}}+1 \Rightarrow \frac{F}{t} \leq \frac{1}{16}$, true for $(F / t, \delta / t) \in \hat{S}$.

$\hat{B}=\{(F / t, \delta / t) \in \hat{S} \mid \hat{\hat{\psi}} \geq G / t \geq \varphi\}$. It is a nonempty set at least for $\frac{1}{18}\left(\frac{1}{3}+2 \frac{\delta}{t}\right)^{2}>\frac{F}{t} \geq \frac{1}{18}\left(\frac{1}{2}+2 \frac{\delta}{t}\right)^{2}$; in fact, $\hat{\hat{\psi}}\left(\frac{1}{18}\left(\frac{1}{2}+2 \frac{\delta}{t}\right)^{2}, \frac{\delta}{t}\right)>\varphi\left(\frac{1}{18}\left(\frac{1}{2}+2 \frac{\delta}{t}\right)^{2}, \frac{\delta}{t}\right)$ for $\delta / t \in \hat{\hat{S}}$. For $(F / t, \delta / t) \in \hat{B}$ the social optimum is $c=1, n=0$ and the market equilibrium ${ }^{8}$ is $c=0, n=2$.

$\hat{C}=\left\{(F / t, \delta / t) \in \hat{S} \mid F / t \geq(\delta / t)^{2}, 0 \leq G / t \leq \min [\varphi, \psi]\right\}$ and it is clearly nonempty. For $(F / t, \delta / t) \in \hat{C}$ the social optimum is $c=1, n=0$ and the market equilibrium is $c=1, n \in\left[n_{11}-1, n_{11}+1\right]$. $\hat{D}=\left\{(F / t, \delta / t) \in \hat{S} \mid(\delta / t)^{2} / 2 \geq F / t \geq((\delta / t) /(1+2 \delta / t))^{2}, \psi \geq G / t \geq \max [0, \hat{\varphi}]\right\}$.

\footnotetext{
${ }^{8}$ Note that an accurate discrete version of $\psi$ would be offered by a piecewise function, increasing in F/t and identical to $\hat{\hat{\psi}}$ for $(1 / 3+2 \delta / t)^{2} / 18>F / t \geq(1 / 2+2 \delta / t)^{2} / 18$. The maximum number of perimeter firms that enter the market when parameters belong to $\hat{B}$ depends $\delta / t$. When $\delta / t \rightarrow 0$, and so $F / t \rightarrow 0$, such a number would tend to infinity.
} 
Since $(\delta / t)^{2}>((\delta / t) /(1+2 \delta / t))^{2}>(\delta / t)^{2} / 2$ for $\delta / t \in \hat{S}$ and $\hat{\varphi}>\varphi, \hat{\psi}>\psi$, it follows that $\hat{D}$ is nonempty. For $(F / t, \delta / t) \in \hat{D}$ the social optimum is $c=0, n=\hat{n}$ and the market equilibrium is $c=1, n \in\left(n_{11}-1, n_{11}\right]$. A sufficient condition ensuring that the long run number of perimeter firms is lower than the socially optimal one is

$n_{11} \leq n_{a} \Rightarrow \sqrt{\frac{t}{F}}-\frac{2 t}{3 \sqrt{2 F t}-2 \delta} \geq 2$, satisfied if

$f=\left(\frac{4 \frac{\delta}{t}-2+3 \sqrt{2}-\sqrt{-48 \sqrt{2} \frac{\delta}{t}+\left(3 \sqrt{2}-2+4 \frac{\delta}{t}\right)^{2}}}{12 \sqrt{2}}\right)^{2} \leq \frac{F}{t} \leq\left(\frac{4 \frac{\delta}{t}-2+3 \sqrt{2}+\sqrt{-48 \sqrt{2} \frac{\delta}{t}+\left(3 \sqrt{2}-2+4 \frac{\delta}{t}\right)^{2}}}{12 \sqrt{2}}\right)^{2}$.

A sufficient condition to ensure that in a subset of $\hat{D}$ the number of perimeter firms is less than the socially optimal one is that $\psi\left(f, \frac{\delta}{t}\right)-\hat{\varphi}\left(f, \frac{\delta}{t}\right)>0$, that is satisfied for any $\frac{\delta}{t} \in[0, \Delta]$. Q.E.D. 